\section{THE INCIDENCE \& PATTERN OF MICRO PERFORATION OF SURGICAL GLOVES AFTER SINGLE USE}

\author{
Parveen Akhter Lone ${ }^{1}$, Mubashar Akram ${ }^{2}$, Azhar Malik Vishal Loona Arif Rashid ${ }^{5}$ \\ ${ }^{1,4,5}$ Department of Oral and Maxillofacial Surgery, IGGDC, Jammu \\ ${ }^{2}$ General Surgeon, K K health Services, Jammu \\ ${ }^{3}$ Department of Conservative Dentistry, IGGDC, Jammu
}

\begin{abstract}
:
Aim \& Objectives: Concern about the transmission of infection from patients to healthcare workers $\&$ vice versa is increasing. According to occupational safety \& Health administration, USA guidelines, gloves must be worn whenever there is reasonable like hood of contact of body fluids of patients to health personnel's in order to prevent contamination. The aim of this study is to report the pattern \& incidence perforation of surgical gloves after single use during different dental \&maxillofacial surgical procedures $\&$ also to compare the perforation rate in single \& double gloving methods during different elective \& emergency oral \& surgical procedures.

Material \& Methods: This prospective study was done for sixmonths in the department of oral \&maxillofacialsurgery. All the gloves used during elective \& emergency, minor \& major surgical procedures were collected .Both visual \& hydro insufflations techniques were used to check the gloves for perforation \& parameters were recorded.

Results: A total of 1000 gloves wererecorded, used in emergency\& elective procedures. The percentage of operating doctor, assistant nurses wasrecorded. $34.54 \%$ gloves used in IMF were perforated.22.14\% gloves used in Trans alveolar extraction with burs and $13.33 \%$ sharp surgical instruments perforated gloves.Suture needles perforated $18 \%$ gloves and needle pricks during extraction perforated $12 \%$ gloves. The overall perforation rate in all surgical procedures mentioned above was $18.62 \%$. The chi square value: 114.129 and $\mathrm{p}$ value $<0.001$.

Conclusions: Double gloving method reduces the risk of contamination from patient to operating staff \& vice versa by reducing the inner glove perforation
\end{abstract}

\section{Research} Article

\author{
Key words: \\ Perforation, Surgical Gloves, \\ Emergency \& Elective \\ Procedures, \\ Tooth Extraction, \\ Bone Cutting Instruments.
}

Source of support : Nil
Conflict of interest: None
INTRODUCTION: Surgical scrubbing preoperatively do not eradicate but reduce the resident flora on operator's hand so the blood borne pathogens can be transmitted from patient to the surgeon \& his team members .The Role of surgical gloves is to prevent the exposure of surgical team, to limit the spread of pathogens from operators hand to the surgical site of patient by creating an aseptic environment thereby minimising the chances of infection $\&$ act as a protective barrier between surgical personnel \&patients against blood borne pathogens such as human immunodeficiency Virus (HIV), Hepatitis (HBV) Hepatitis C. ${ }^{1}$ The surgical gloves were introduced in late $1880 \&$ since then they have played a vital role in preventing cross infection.[2,3,4] So the surgical gloves are important for maintaining sterile atmosphere in operating procedures \& operating room. Glove perforation therefore means that the protective barrier is compromised leading to route to surgical personnel getting contaminated by patients body fluids The frequency of glove perforation depends upon the type of surgery done, duration of surgery , experience of surgeon[5,6]. Glove perforation is very common \& can reach even up to $78 \%$ while performing emergency procedures. ${ }^{7}$ Literature has reported that glove perforation ranged from $7 \%$ in urological surgery to $65 \%$ in cardiac surgery, $10 \%$ in ophthalmic surgery \& $50 \%$ in general surgeries. $[8,9]$

Rate of perforation is found much higher in emergency procedures than elective procedures[10,11]. one of the major challenge reported in literature is that $70 \%$ of operating staff is not aware of perforation until procedure is completed[2].

In oral \& maxillofacial procedures teeth extractions, minor oral surgical procedures under local anaesthesia\& major surgical procedures of oral cavity including trauma, temporomandibular joint surgeries, and maxillofacial reconstruction, orthognathic \& cancer surgeries are done under general anaesthesia. In addition to syringes being used for injecting local anaesthesia\& irrigation of oral cavity \& surgical site, different bone cutting \& sharp instruments like micrometer \& surgical burs, stainless steel wires \& cutter, chisel \& mallet,Bp blades, gigli saw \& suturing instruments are used which cause glove perforations. Hence the aim of present study was to report the rate of perforations of surgical gloves to reduce the health risks to the health personnel's \& 
prevent the operating staff from contamination of infected blood Saliva \& other fluids of patients

MATERIAL \& METHODS: This prospective study was conducted in department of oral \& maxillofacial surgery from April 2018 to October 2018. The department is treating daily 100-150 patients including trauma \& emergency cases, extraction of teeth, minor\& major surgical surgeries under local \& general anaesthesia. Consultants, senior resident's interns house surgeon's students \& nursing staff. Staff having any skin ailments or abrasions was excluded from study.The gloves used by each health professionals for each procedures were collected in labelledboxes. The members of surgical team placed their used gloves immediately after completing surgical procedures .Gloves from all boxes from operating rooms were collected $\&$ taken for testing $\&$ data collection every day.

\section{Two techniques were used for testing $[12,13]$}

A Visual; each glove was inspected visually for perforations

B Hydro insufflations; Each glove was checked by standardised water leak test. Gloves were filled with $1000 \mathrm{ml}$ solution of betadine with water. Manual compression on the wrist of gloves for 1-2 minutes to show any hole with leaking of brown water indicating perforation was done the location of perforation, no of perforations \& size of perforation was recorded. The data was analysed by statistical analysis. Surgical team comprised of principal surgeon, assistant surgeons, \& scrub nurses.

Duration of procedure was recorded. Cases in which perforation of gloves in any member was detected intra operatively \& those in which glove change was performed, cases lasting more than 30 minutes. The glove perforation was assessed against the following parameters.

At whether (a) surgeon, scrub nurse or assistant had a perforation (b) type of surgery (c) duration of surgery (d) elective or emergency surgery (e) site \& no of perforation

\section{RESULTS:}

A total of 1000 gloves were used out of which perforations were detected in $18.62 \%$. It was most frequent in single group followed by outer glove of double glove group \& was seen least in inner glove of double glove group. The percentage of operating doctor, assistant nurses was recorded. $34.54 \%$ gloves used in IMF were perforated. $22.14 \%$ gloves used in Tran's alveolar extraction with burs and $13.33 \%$ sharp surgical instruments perforated gloves. Suture needles perforated $18 \%$ gloves and needle pricks during extraction perforated $12 \%$ gloves. The overall perforation rate in all surgical procedures mentioned above was $18.62 \%$.The chi square value: 114.129 and $p$ value $<0.001$.

The duration of surgery was divided as procedures less than 60 minutes \& those lasting for more than one hour. Perforation rate was more in procedures lasting for more than one hr compared to those lessthan one hr. The incidence of perforation of gloves was much higher in elective than emergency surgeries

The present study shows that one third of all surgeries had perforation in one person in surgical team. There is no statically difference incidence of perforation in single glove $\&$ outer glove of the double glove. However the inner glove of double glovehad lesser perforation amongst the surgeon's assistants \& nurses.

Table 1: Comparison of the presence or absence of perforations from the gloves assessed while performing different oral surgical procedures using chi square test

\begin{tabular}{|c|c|c|c|c|}
\hline \multirow{2}{*}{\multicolumn{2}{|c|}{ Type of oral surgical procedure }} & \multicolumn{2}{|c|}{ Perforations } & \multirow{3}{*}{\begin{tabular}{|l} 
Total \\
440
\end{tabular}} \\
\hline & & \multirow{2}{*}{\begin{tabular}{|l|} 
Present \\
152 \\
\end{tabular}} & \multirow{2}{*}{\begin{tabular}{|l} 
Absent \\
288
\end{tabular}} & \\
\hline \multirow[b]{2}{*}{ IMF } & Count & & & \\
\hline & $\%$ within group & $34.54 \%$ & $65.45 \%$ & $100.0 \%$ \\
\hline \multirow{2}{*}{$\begin{array}{l}\text { Surgical burs in } \\
\text { disimpactions }\end{array}$} & Count & 124 & 436 & 560 \\
\hline & $\%$ within group & $22.14 \%$ & $77.86 \%$ & $100.0 \%$ \\
\hline \multirow{2}{*}{\begin{tabular}{|l|} 
Due to sharp surgical \\
instruments
\end{tabular}} & Count & 60 & 390 & 450 \\
\hline & $\%$ within group & $13.33 \%$ & $86.67 \%$ & $100.0 \%$ \\
\hline \multirow{2}{*}{ Suture needle prick } & Count & 90 & 410 & 500 \\
\hline & $\%$ within group & $18.0 \%$ & $82.0 \%$ & $100.0 \%$ \\
\hline \multirow{2}{*}{$\begin{array}{l}\text { Needle prick during } \\
\text { extractions }\end{array}$} & Count & 114 & 836 & 950 \\
\hline & $\%$ within group & $12.0 \%$ & $88.0 \%$ & $100.0 \%$ \\
\hline \multirow{2}{*}{ Total } & Count & 540 & 2360 & 2900 \\
\hline & $\%$ within group & $18.62 \%$ & $81.38 \%$ & $100.0 \%$ \\
\hline
\end{tabular}

$(\mathrm{P}<0.05$ - Significant*, $\mathrm{p}<0.001$ - Highly significant**)

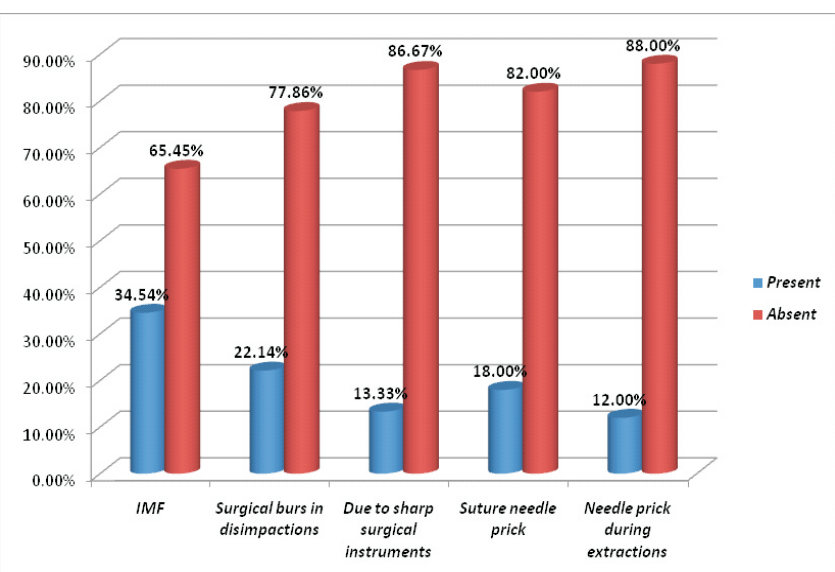

DISCUSSION: Glove perforation during surgical procedure is a very common event $\&$ most of the time operating staff is unaware of perforation till procedure is complete. A breach in glove of operating staff increases the potential for cross infection, increases the possibility of needle stick \& injuries due to sharp instruments \& also the inoculation of surgeon with infected body fluids[14]. operating staff have minor unnoticed cuts on their hands making them exposed to contacting infectious diseases from patients if surgical gloves are perforated [15].

Studies have reported that gloves are punctured in different ways \& occur most commonly during wound closure \& poor assistance by operating team nurses, assistant doctor[16,17]. However oral \& maxillofacial surgery procedure includes injecting local aestheticsolution, extraction of teeth, minor \& major surgical procedures \&closure of wounds. The incidence of glove puncture in our study was $18.62 \%$ comparable to studies showing perforation rate of $7.7-24 \%{ }^{14}$. Glove perforation reported in other surgical specialities vary with different procedures like gynaecology $10.1-43 \%$ in general surgery $35-54 \%$ in plastic surgery $21.4 \%$ \& in 
thoracic surgery $26 \%{ }^{18}$.Use of metallic instruments ,oscillating saw, sharp instrument \& wires in orthopaedic implant surgeries lead to high risk of glove perforation in those procedures[19]. Similar to the present study the oral \& maxillofacial procedures include extraction of teeth, orthopaedic, plastic \& reconstructive procedures. Like treatment of fractures using sharp wires, bone drilling \& cutting instruments, oscillatingsaw, knives use of syringes \& needles lead to higher rate of glove puncture. The present study reveal the highest rate of puncture in principal surgeon gloves because sharp instruments are used by them more than other assistants\& scrub nurses[20]. Literature has revealed that gloves of left hand perforations are more than right hand[10,21].

The present study reveals that the rate of glove perforation is high in both elective \& emergency procedures. The overall rate of $18.62 \%$ perforation is much higher reported by previous studies[21-22].

Perforations rate of gloves at different layers rate of perforation in inner layer in the present study is less than outer layer perforation. The outer layer provides sufficient protection against cross infections in most surgical procedure .Literature also has reported that the use of double gloves markedly reduces the risk of cross infection by body fluids during surgical procedures as compared to single gloving $[19,23]$.Studies also have demonstrated that inner glove perforation rate reduces from $20.8 \mathrm{t} 02.5 \%$ for operating team members when they use double gloves[24] similar to present study where the double gloving reduced the perforations of inner gloves which prevented the contamination of blood \& saliva.

The perforation were seen much higher while doing the procedures like use of stainless steel wires, needle stick during injections of local anaesthesia ,using surgical burs \& micrometer while doing bone cutting procedures \& bone plating, \& resections by gilisaw .

The present study reported the higher incidence of perforation in main surgeon followed by scrub nurse. This may be due to direct exchange of sharp surgical instruments \& needles between these two thereby increasing the risk of perforation in both, first than $2^{\text {nd }} \&$ third assistant similar to the previous studies[10.11.21].

Previous studies have reported that incidence of glove perforation of surgeons increased with the duration of surgery that is surgeries lasting for more than ninetyminutes had greater rate of perforations, these perforations represent higher risk of surgeons because of longer time of exposure to blood contact . Glove perforation with longer duration of surgery has also been recognised by partecke et al \&association of scientific medical societies in Germany have recommended a change in gloves after 90 minutes for daily routine in surgical setting[25].

CONCLUSION: The present study has shown that there is markedly high rate of glove perforation at our centre during elective as well as emergency procedures using single gloves $\&$ risk of contamination to infected blood \& saliva is very high. Hence the use of double gloving is recommended in order to maintain sterility \& prevent the operating staff. The main surgeon is most prone to perforations especially in surgical procedures lasting for more than one hour so intraoperative gloves should be changed .Extra care should be taken while giving injections for local anaesthesia\&irrigating the surgical site to prevent the needle stick injuries \& while using stainless steel wires, sharp instruments \& surgical burs for different orofacial surgical procedures . Also glove checks after \& during procedures are recommended in case of any suspected glove perforation in order to take necessary steps to avoid contamination to the operating staff.

Acknowledgement: Authors acknowledge \& thank Zain ul Arifeen, Ayesha Nisar, Maryam\& Ayera Bashir for their help.

\section{REFERENCES:}

1. Occupational exposure to bloodborne pathogens-OSHA. Final rule. Fed Regist 1991;56:64004-182.

2. Osman MO, Jensen SL. Surgical gloves: current problems. World J Surg. 1999;23:630-7.View Article PubMedGoogle Scholar

3. Jamal A, Wilkinson S. The mechanical and microbiological integrity of surgical gloves. ANZ J Surg. 2003;73:140-3.View ArticlePubMedGoogle Scholar

4. Cole RP, Gault DT. Glove perforation during plastic surgery. Br J Plast Surg. 1989;42:481-3.View ArticlePubMedGoogle Scholar

5. Rele M, Mathur M, Turbadkar D. Risk of needle stick injuries in health care workers - A report. Indian J Med Microbiol 2002;20:206-7.

6 Avery CM, Taylor J, Johnson PA. Double gloving and a system for identifying glove perforations in maxillofacial trauma surgery. Br J Oral MaxillofacSurg 1999;37:316-9.

7 Bukhari SS, Harrison RA, Sanderson PJ. Contamination of surgeons glove fingertips during surgical operations.

J Hosp Infect. 1993;24:117-21.View Article PubMed Google Scholar

8 Pitten FA, Herdemann G, Kramer A. The integrity of latex gloves in clinical dental practice. Infection. 2000;28(6):388-92.View Article PubMedGoogle Scholar

9 Dodds RD, Guy PJ, Peacock AM, Duffy SR, Barker SG, Thomas MH. Surgical glove perforation. Br J Surg 1988;75:966-8.

10 Malhotra M, Sharma JB, Wadhwa L, Arora R. Prospective study of glove perforation in obstetrical and gynecological operations: are we safe enough? J Obstet Gynaecol Res. 2004;30(4):319-22.View Article Pub MedGoogle Scholar 
11 Solda S, et al. Undetected perforations of surgical gloves during emergency procedures. Rev Assoc Med Bras. 2009;55(5):597-600.View Article PubMedGoogle Scholar

12 Reichman DE, Greenberg JA. Reducing surgical site infections: a review. Rev Obstet Gynecol. 2009;2(4):212-21.PubMedPubMed CentralGoogle Scholar

13 Pieper SP, Schimmele SR, Johnson JA, Harper JL. A prospective study of the effcacy of various gloving techniques in the application of Erich arch bars. J Oral Maxillofac Surg. 1995;53:1174-6.View Article PubMedGoogle Scholar

14 Bekele A, Shiferaw S, Gulilat D. Levels and trends of occupational hazards among surgical residents at TikurAnbessa Hospital, Addis Ababa Ethiopia. East Central Afr J Surg. 2013;18:3.Google Scholar

15 Hussain SA, Latif ABA, Choudhary AA. Risk to surgeons: a survey of accidental injuries during operations. Br J Surg. 1988;75:314.View Article PubMedGoogle Scholar

16 Barbosa MV, Nahas FX, Ferreira LM, Farah AB, Ayaviri NA, Bariani RL. Risk of glove perforation in minor and major plastic surgery procedures. Aesthetic PlastSurg 2003;27:481-4

17 Driever R, Beie M, Schmitz E, Holland M, Knapp M, Reifschneider HJ, et al. Surgical glove perforation in cardiac surgery. ThoracCardiovascSurg 2001;49:328-30

18 Dhar D. Occult glove perforation during adult elective orthopaedic surgery. Maced J Med Sci 2011;4:399-402

19 Thomas S, Agarwal M, Mehta G. Intraoperative glove perforation-Single versus double gloving in protection against skin contamination. Postgrad Med J 2001;77:458-60

20 Tanner J, Parkinson H. Double gloving to reduce surgical cross-infection. Cochrane Database Syst Rev. 2002;3:CD003087

21 Green SE, Gompertz RH. Glove perforation during surgery: what are the risks? Ann R CollSurg Engl. 1992;74(5):306-8.PubMedPubMed CentralGoogle Scholar

22 Hamer AJ. Electronic device for the detection of breaches in asepsis during surgical procedures. BrJ Surg. 1987;74:10389. View ArticleGoogle Scholar

23 Naver LP, Gottrup F. Incidence of glove perforations in gastrointestinal surgery and the protective effect of double gloves: a prospective, randomized controlled study. Eur J Surg. 2000;166:293-5.View Article PubMedGoogle Scholar

24 Gani JS, Anseline PF, Bissett RL. Efficacy of double versus single gloving in protecting the operating room team. Aust NZ J Surg. 1990;60:171-5.25Google Scholar7

25 Partecke LI, Goerdt AM, Langner I, Jaeger B, Assadian $\mathrm{O}$, Heidecke CD, et al. Incidence of microperforation for surgical gloves depends on duration of wear. Infect Control HospEpidemiol 2009;30:409-14.

\section{CORRESPONDING AUTHOR:}

Dr. Parveen Akhter Lone

Professor \& HOD OMFS,

Indira Gandhi Government Dental College

Jammu (IGGDCJ)

Email : parveenlone@gmail.com 